\title{
Degradation of oil products in a soil from a Russian Barents hot-spot during electrodialytic remediation
}

\author{
Kristine B. Pedersen ${ }^{1}$, Tore Lejon ${ }^{1 *}$, Pernille E. Jensen ${ }^{2}$ and Lisbeth M. Ottosen²
}

\begin{abstract}
A highly oil-polluted soil from Krasnoe in North-West Russia was used to investigate the degradation of organic pollutants during electrodialytic remediation. Removal efficiencies were up to $70 \%$ for total hydrocarbons (THC) and up to $65 \%$ for polyaromatic hydrocarbons (PAH). Relatively more of the lighter PAH compounds and THC fractions were degraded. A principal component analysis (PCA) revealed a difference in the distribution of PAH compounds after the remediation. The observed clustering of experiments in the PCA scores plot was assessed to be related to the stirring rate. Multivariate analysis of the experimental settings and final concentrations in the 12 experiments revealed that the stirring rate of the soil suspension was by far the most important parameter for the remediation for both $\mathrm{THC}$ and $\mathrm{PAH}$. Light was the second most important variable for PAH and seems to influence degradation. The experimental variables current density and remediation time did not significantly influence the degradation of the organic pollutants. Despite current density not influencing the remediation, there is potential for degrading organic pollutants during electrodialytic removal of heavy metals, as long as a stirred set-up is applied. Depending on remediation objectives, further optimisation may be needed in order to develop efficient remediation strategies.
\end{abstract}

Keywords: Electrokinetic remediation, PLS, PCA, Oil pollution, PAH

\section{Background}

Electrodialytic remediation (EDR) is a technology viable for removing heavy metals from polluted soil (Ottosen et al. 1997); the effect on organic pollutants has yet to be investigated. EDR is based on the principles of electrokinetic remediation (EKR) in which an electric field is applied directly to the soil and electrolysis reactions at the inert electrodes produces protons at the anode and hydroxyl ions at the cathode (Acar and Alshawabkeh 1993). An acidic front formed at the anode dominates the system, mainly due to higher effective ionic mobility of protons compared to hydroxyl ions (Acar and Alshawabkeh 1993). Transport processes in the soil under the influence of an electric field include electromigration (transport of ions in solution), electroosmosis (transport

\footnotetext{
*Correspondence: tore.lejon@uit.no

${ }^{1}$ Department of Chemistry, University of Tromsø, The Arctic University of Norway, Postbox 6050, 9037 Langnes, Troms $\varnothing$, Norway

Full list of author information is available at the end of the article
}

of fluid through pores), electrophoresis (transport of charged particles) and diffusion (Acar and Alshawabkeh 1993; Acar et al. 1993).

The coupling of EKR with bioremediation has been shown to increase removal efficiencies of hydrophobic organic contaminants such as polyaromatic hydrocarbons $(\mathrm{PAH})$ and total petroleum hydrocarbons (TPH) in soil/sediments (Dong et al. 2013; Gill et al. 2014; Kim et al. 2010; Li et al. 2012; Lohner et al. 2009; NiquiArroyo et al. 2006; Wang et al. 2013; Wick 2009). The bioavailability of hydrophobic contaminants is increased by advancing contact between the catabolically active microorganisms, nutrients, electron donors/acceptors and contaminants. Transport of nutrients and electron donors/acceptors is dominated by electromigration, while the transport of hydrophobic contaminants is dominated by electroosmosis (Gill et al. 2014; Lohner et al. 2009; Wick 2009). Microorganisms may be transported via electroosmosis and/or electrophoresis depending on their properties; e.g. weakly charged bacteria are

\section{㩏 Springer}

(c) 2016 Pedersen et al. This article is distributed under the terms of the Creative Commons Attribution 4.0 International License (http://creativecommons.org/licenses/by/4.0/), which permits unrestricted use, distribution, and reproduction in any medium, provided you give appropriate credit to the original author(s) and the source, provide a link to the Creative Commons license, and indicate if changes were made. 
primarily transported by electroosmosis (Wick 2009). Increasing the bioavailability of contaminants depends on the types of microorganisms as well as the physicochemical properties of the given chemical (Gill et al. 2014). Enhancement of the combined EK-biodegradation process includes the external introduction of nutrients, microorganisms that degrade the targeted contaminants and surfactants to increase the mobility of contaminants and/or microorganisms (Dong et al. 2013; Gill et al. 2014; Lohner et al. 2009). The electrolysis reactions (Fig. 1) may also be used to increase degradation adjacent to the electrodes, in which $\mathrm{H}_{2}$ acts as electron donors and $\mathrm{O}_{2}$ acts as electron acceptors (Lohner et al. 2009).

Many studies within EK-biodegradation have been based on spiked soils and reported high removal efficiencies of the spiked soils have not been possible to reproduce for historically polluted soil samples. However, removal efficiencies of up to $60 \%$ of TPH in natural soils has been reported (Dong et al. 2013), while removal efficiencies of PAH are low. The addition of surfactants for the mobilisation of PAH has proven to increase removal efficiencies of aged contaminated soil/sediments to $30 \%$ (Colacicco et al. 2010; Dong et al. 2013; Li et al. 2012; Niqui-Arroyo et al. 2006; Wang et al. 2013).

The influence of applying an electric field on microbial communities has mainly been assessed by regarding the contaminant degrading bacteria, and generally limited affect has been detected (Dong et al. 2013; Li et al. 2012; Lohner et al. 2009; Mena et al. 2014; Shi et al. 2008a, b; Wick et al. 2004), and may even stimulate microbial activity (Shi et al. 2008b). Negative impacts on microorganisms during EKR have however been observed and since these occurred adjacent to electrodes, this was attributed to changes in $\mathrm{pH}$ rather than the influence of the direct current (Kim et al. 2010; Schmidt et al. 2007).

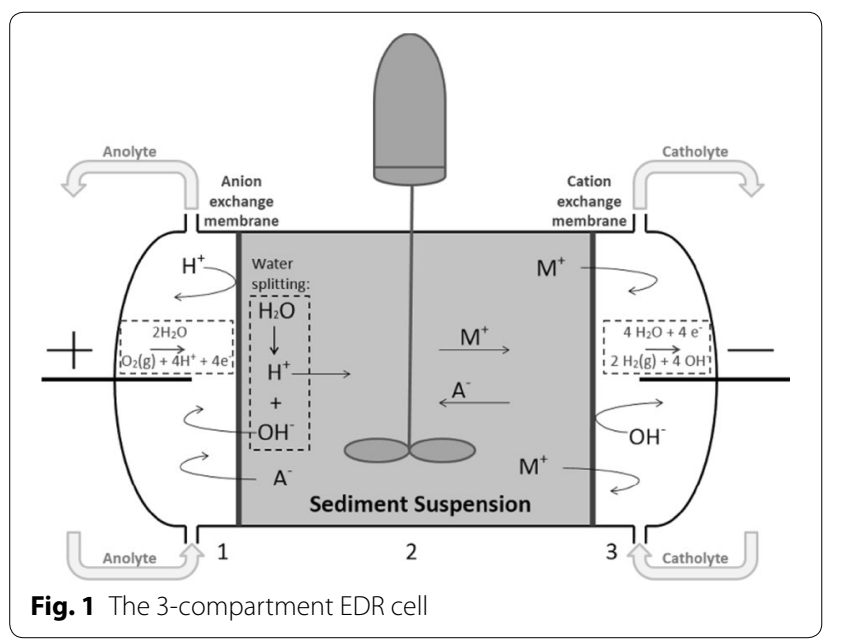

Wick et al. found that the electrodes may inhibit microbial communities if not physically shielded (Wick et al. 2004). In addition, chlorine and hydrogen peroxide can be generated in secondary electrode reactions and may inhibit microbial communities adjacent to the electrodes (Gill et al. 2014).

In EDR, ion exchange membranes are used to control transport between electrolytes and the polluted soil; in the 3-compartment cell as used in this study (Fig. 1), ions and compounds generated from reactions at the electrodes are prevented from entering the polluted soil. Acidification of the soil still occurs, mainly due to water splitting at the anion exchange membrane (Ottosen et al. 2000). Stirring the sediments has been shown to significantly improve removal efficiencies of heavy metals compared to the stationary cell set-up (Ottosen et al. 2012). Applying a stirred cell set-up may potentially influence the removal of organic contaminants due to increased aeration and mixing possibly resulting in increased bioavailability of the contaminants; Lima et al. for instance reported removal efficiencies of up to $79 \%$ for PAH in a stirred set-up combined with use of surfactants (Lima et al. 2012).

Multivariate design and analysis provide tools for identifying trends and correlations in a system, including variable importance. A complete two-level factorial design contains all possible combinations of the settings, resulting in all variables as well as variable interactions being modelled. A fractional factorial design is constructed as a fraction of a complete factorial design, thus yielding less information as some variables will be confounded with other variables. It is however still possible to construct the design so that main effects and two-variable effects are only confounded with higher order interaction effects. Since higher order interaction effects are assumed to be negligible, the fractional designs can be used to obtain good estimates of the true main effects and the true two-variable interaction effects (Carlson and Carlson 2005). In most studies the identification and setting/tuning of the most important variables will be sufficient for obtaining satisfactory results but there are methods of extracting more information from the data, e.g. by employing the experimental variables as input in Projections onto Latent Structures (PLS) analysis.

In Projections onto Latent Structures (PLS), the quantitative relation between a descriptor matrix, $\mathrm{X}$ and a response matrix, $\mathrm{Y}$ is calculated. In this study PLS is hence used to establish the quantitative relation between experimental settings and final concentrations; the model subsequently used to retrieve the comparative influence of the experimental variables. PLS is based on projections providing the possibility of having more variables than objects. Other advantages of PLS include simultaneously 
modelling several responses, coping with collinearity between variables, noise in both the $\mathrm{X}$ and $\mathrm{Y}$ matrices, coping with moderate amounts of missing data $(<20 \%)$ and providing plots of the data compressed to fewer dimensions than the original dataset (Abdi 2010; Carlson and Carlson 2005; Trygg and Wold 2002; Wold et al. 2001).

In EDR studies, PLS has been used to identify the comparative importance of experimental variables (Pedersen et al. 2015c, d), determine sediment-specific optimal settings and has in addition been proven a good method for predicting experimental settings for new sediments when data from several sediments has been compiled (Pedersen et al. 2015b).

The objectives of this study were to investigate possible degradation of heavily oil polluted soil, including PAH compounds during EDR and in addition applying multivariate analysis to determine the influence of the experimental settings, including current density, remediation time, liquid-solid (L/S) ratio and light/no light.

\section{Experimental}

\section{Description of site and experimental sample}

The land plot Cape Knevatyi is a man-made part of Nikolsky Island located in the Northern Dvina River, Arkhangelsk, NW Russia. The land plot was constructed in 1966 with a size of approximately $60,000 \mathrm{~m}^{2}$ and has since been reduced to an area of $30,000 \mathrm{~m}^{2}$ due to erosion into the river. In the 1970s the land plot was used as storage site for oil-contaminated water, discharged into on-site pits from vessels. There are three ground pits with diameters of approximately $15-50 \mathrm{~m}$ located $20-100 \mathrm{~m}$ from the river. The oil pollution has been observed to have dispersed to the river bank which erodes into the river. The Northern Dvina River contributes $70 \%$ of river water to the White Sea hence providing a direct path of pollution from Cape Knevatyi to the White Sea.

Pollution with TPH was observed to cover an area of approximately $2500 \mathrm{~m}^{2}$ and to depths of approximately $3 \mathrm{~m}$. Hotspot areas were observed in the topsoil layer in the depths $0.5-1.5 \mathrm{~m}$. Soil used in this study was sampled from hotspot at depths of 1.0-1.5 m by drilling (ø63 mm). The samples were kept cool during transport and were stored in a freezer until use/analysis.

\section{Analytical}

Major elements and heavy metal concentrations (P, $\mathrm{Al}$, $\mathrm{Ca}, \mathrm{Fe}, \mathrm{K}, \mathrm{Mg}, \mathrm{Mn}, \mathrm{Na}, \mathrm{V}, \mathrm{Cr}, \mathrm{Cu}, \mathrm{Ni}, \mathrm{Pb}, \mathrm{Zn}$ ) were measured based on digestion (Danish standard DS259). Sediment dried at $105^{\circ} \mathrm{C}(1.0 \mathrm{~g})$ and $\mathrm{HNO}_{3}(9 \mathrm{M}, 20 \mathrm{~mL})$ were autoclaved $\left(200 \mathrm{kPa}, 120^{\circ} \mathrm{C}, 30 \mathrm{~min}\right)$. Solid particles were subsequently removed by vacuum filtration through a $0.45 \mu \mathrm{m}$ filter and the liquid was diluted to $100 \mathrm{~mL}$. Metal concentrations in the liquid were measured by Inductively Coupled Plasma-Optical Emission Spectrometry (ICP-OES).

Organic components (PAH, PCB, THC) were measured by ISO/DIS 16703 externally at a licensed laboratory, Eurofins in Moss, Norway.

Carbonate content was measured by treating dried sediment $(5.0 \mathrm{~g})$ with $\mathrm{HCl}(3 \mathrm{M} ; 20 \mathrm{~mL})$ and the developed $\mathrm{CO}_{2}$ was measured volumetrically in a Scheibler apparatus, calibrated with $\mathrm{CaCO}_{3}$.

Organic matter was based on loss of ignition of dried sediment $(2.5 \mathrm{~g})$ being heated at $550{ }^{\circ} \mathrm{C}$ for an hour.

$\mathrm{pH}(\mathrm{KCl})$ Dried sediment $(5.0 \mathrm{~g})$ was agitated with $\mathrm{KCl}$ $(1 \mathrm{M}, 12.5 \mathrm{~mL})$ for an hour and $\mathrm{pH}$ was subsequently measured using a radiometric analytical electrode.

Conductivity Dried sediment $(5.0 \mathrm{~g})$ was agitated with distilled water $(25 \mathrm{~mL})$ for an hour and the conductivity was subsequently measured using a radiometric analytical electrode.

Chloride content was measured by agitating sediment $(10 \mathrm{~g})$ dried at $40{ }^{\circ} \mathrm{C}$ with micropore water $(40 \mathrm{~mL})$ for $20 \mathrm{~h}$. Solid particles were removed by $0.45 \mu \mathrm{m}$ vacuum filtration and the chloride concentration was measured by ion chromatography.

Total Carbon (TC) and Sulphur (S) were measured by high temperature combustion. Dried sediment $(0.5 \mathrm{~g})$ was combusted $\left(1350{ }^{\circ} \mathrm{C}\right)$ converting all carbon and sulphide into carbon dioxide and sulphur dioxide, respectively. The gasses were passed through scrubber tubes to remove interferences and the carbon dioxide and sulphur dioxide were measured by infrared detector.

Nitrogen $(\mathrm{N})$ was measured by the Kjeldahl method. Dried sediment $(1.0 \mathrm{~g})$ was heated to $370{ }^{\circ} \mathrm{C}$ with $\mathrm{H}_{2} \mathrm{SO}_{4}$ (conc., $15 \mathrm{~mL}$ ) and $\mathrm{K}_{2} \mathrm{SO}_{4}(7 \mathrm{~g})$ until white fumes were observed (approx. $90 \mathrm{~min}$ ) and subsequent to cooling $250 \mathrm{~mL}$ distilled water was added to the mixture. $\mathrm{pH}$ of the mixture was raised by adding $\mathrm{NaOH}(45 \%)$ and subsequently the mixture was distilled and the vapours were trapped in $\mathrm{HCl}(15 \%, 85 \mathrm{~mL})$. The trapped vapour solution was subsequently titrated with $\mathrm{NaOH}(5 \mathrm{M})$.

Grain size was measured by wet sieving and dry sieving. Wet sediment $(75 \mathrm{~g})$, distilled water $(350 \mathrm{~mL})$ and $\mathrm{Na}_{4} \mathrm{P}_{2} \mathrm{O}_{7} 10 \mathrm{H}_{2} \mathrm{O}(0.1 \mathrm{M}, 10 \mathrm{~mL})$ were agitated for $24 \mathrm{~h}$. The slurry was then sieved through a $63 \mu \mathrm{m}$ sieve and the fraction above $63 \mu \mathrm{m}$ was subsequently dried and sieved for $15 \mathrm{~min}$ in a mechanical shaker using sieves with screen openings of $0.063,0.080,0.125,0.25,1.0$ and $2.0 \mathrm{~mm}$. The slurry fraction below $63 \mu \mathrm{m}$ was transferred to Andreasen pipette for gravitational sedimentation. Stoke's law was used for estimating the time required for particles to settle $20 \mathrm{~cm}$ and samples representing the sizes $40,32,16,8,4,2$ and $1 \mu \mathrm{m}$ were measured. 


\section{EDR experiments Materials}

The electrodialytic cell was manufactured from Plexiglass and consisted of 3 compartments; the centre compartment contained the polluted soil suspension and electrolyte liquids were circulated in the two adjoining compartments via external flasks (non-sealed). A schematic illustration of the cell design is shown in Fig. 1. The dimensions were; electrolyte compartment length $3.5 \mathrm{~cm}$; centre compartment $10 \mathrm{~cm}$; all compartments had inner diameter of $8 \mathrm{~cm}$. Ion exchange membranes from Ionics (anion 204SZRAB02249C and cation CR67HUYN12116B) separated the electrolyte compartments from the centre compartment. $\mathrm{NaNO}_{3}(0.01 \mathrm{M})$ was used as electrolyte and was regularly adjusted to $\mathrm{pH} 2$ by $\mathrm{HNO}_{3}(5 \mathrm{M})$. Electrolytes (350 mL) were circulated via Ismatec reglo pump with flow rate of $10 \mathrm{~mL} / \mathrm{min}$. Platinum coated titanium electrodes were used and a power supply (Hewlett Packard E3612A) maintained a constant DC current. A CATR14 motor with a stirrer consisting of plastic flaps $(4 \mathrm{~cm} \times 0.5 \mathrm{~m})$ fastened to a glass rod ensured stirring of the soil suspension. No light conditions in selected experiments were obtained by covering the EDR cell in tin foil. The experiments were conducted at room temperature, around $20^{\circ} \mathrm{C}$.

After EDR experiments, the suspension liquid was decanted and organic and inorganic content in the sediment were analysed.

\section{Design}

The experimental design included the continuous variables current density, remediation time, stirring rate and liquid-solid (L/S) ratio and the discrete variable light/no light. Undertaking a complete two-level factorial design would entail conducting $2^{5}$ (32) experiments. By assuming that the interaction effects between 4 and 5 factors are negligible, the number of experiments can be reduced to a $2^{5-2}$ fractional design consisting of 8 experiments (no. 1-8). In addition, 4 experiments (no. 9-12) were conducted in the centre point of the experimental domain of the continuous variables. The experimental settings are presented in Table 1.

\section{Multivariate modelling}

In this study, SimcaP11 was used for PCA and PLS modelling based on the experiments in Table 1 . In calculation of a PCA model, the X matrix consisted of the concentrations of PAH compounds before and after the experiments. In the PLS models, the X-matrix consisted of the experimental settings and the $\mathrm{Y}$ matrix consisted of the final concentrations of organic pollutants. In order to include the discrete variable light/no light in the models,
Table 1 Experimental design

\begin{tabular}{llrrrl}
\hline $\begin{array}{llll}\text { Exp } \\
\end{array}$ & $\begin{array}{l}\text { Current density Time (h) } \\
\left(\mathbf{m A} / \mathbf{c m}^{\mathbf{2}}\right)\end{array}$ & $\begin{array}{l}\text { Stirring rate } \\
(\mathbf{r p m})\end{array}$ & L/S (mL/g) & Light \\
\hline 1 & 0 & 48 & 1300 & 4 & Light \\
2 & 0.1 & 48 & 100 & 4 & No light \\
3 & 0 & 432 & 100 & 4 & Light \\
4 & 0.1 & 432 & 1300 & 4 & No light \\
5 & 0 & 48 & 1300 & 2 & No light \\
6 & 0.1 & 48 & 100 & 2 & Light \\
7 & 0 & 432 & 100 & 2 & No light \\
8 & 0.1 & 432 & 1300 & 2 & Light \\
9 & 0.05 & 240 & 700 & 3 & Light \\
10 & 0.05 & 240 & 700 & 3 & No light \\
11 & 0.05 & 240 & 700 & 3 & Light \\
12 & 0.05 & 240 & 700 & 3 & No light \\
\hline
\end{tabular}

the two conditions were arbitrarily assigned a value of 1 or -1 .

Correlation factors (R2X and R2Y) and predictive powers were used to evaluate the reliability of the multivariate models. $\mathrm{R} 2 \mathrm{X}$ is a measure of the fraction of the $\mathrm{X}$ matrix explained by the model while $\mathrm{R} 2 \mathrm{Y}$ is a measure of the fraction of the Y matrix explained by the model and Q2 is an estimate of the reliability of the model calculated by cross-validation. Variable Importance in the Projection (VIP) plots are absolute values that present the importance of each parameter in a given model with respect to its correlation to all the responses $(\mathrm{Y})$ and to the projection $(\mathrm{X})$ and were used to assess variable importance in the remediation. Parameters with VIP values above 1 are considered significant for explaining the responses; VIP values between 0.5 and 1 indicate a moderate influence on the model and parameters with VIP values below 0.5 have a low influence on the model. Contour plots were used to assess whether important variables had positive/ negative influence on the models.

\section{Results and discussion}

\section{Soil characteristics}

The soil used for the EDR experiments exhibited low content of carbonate and organic matter indicating a low buffer capacity (Table 2). The concentrations of metals were also low, which may be due to the low content of clay and silt $(<2 \%)$ in the soil.

The concentrations of hydrocarbons were high, especially the heavier fractions $\mathrm{C}_{12}-\mathrm{C}_{35}$, and the total concentration of hydrocarbons were equivalent to more than 20 times the Russian soil quality criteria. During the sampling, a strong odour of oil products and free phase oil in the subsurface water in the drilling hole was observed. The sampled soil did not contain large amounts of peat 
Table 2 Sediment characteristics

\begin{tabular}{|c|c|c|c|}
\hline Characteristic & Units & Value & Russian QC \\
\hline Carbonate & $\%$ & $0.3 \pm 13 \%$ & \\
\hline Organic matter & $\%$ & $2.8 \pm 8 \%$ & \\
\hline Total carbon & $\%$ & $2.5 \pm 2 \%$ & \\
\hline Total sulphur & $\%$ & $0.06 \pm 5 \%$ & \\
\hline Nitrogen & $\%$ & $0.03 \pm 2 \%$ & \\
\hline $\mathrm{pH}$ & & $3.9 \pm 1.5 \%$ & \\
\hline Conductivity & $\mathrm{mS} / \mathrm{cm}$ & $0.08 \pm 6 \%$ & \\
\hline Chloride & $\mathrm{mg} / \mathrm{kg}$ & $8.6 \pm 30 \%$ & \\
\hline \multicolumn{4}{|l|}{ Grain size } \\
\hline Clay & $\%$ & 0.6 & \\
\hline Silt & $\%$ & 1.1 & \\
\hline Sand & $\%$ & 97.9 & \\
\hline Rubble & $\%$ & 0.4 & \\
\hline $\mathrm{Al}$ & $\mathrm{mg} / \mathrm{kg}$ & $830 \pm 9 \%$ & \\
\hline $\mathrm{Ba}$ & & $33 \pm 39 \%$ & \\
\hline $\mathrm{Ca}$ & & $190 \pm 22 \%$ & \\
\hline $\mathrm{Fe}$ & & $1650 \pm 7 \%$ & \\
\hline K & & $150 \pm 20 \%$ & \\
\hline $\mathrm{Mg}$ & & $140 \pm 20 \%$ & \\
\hline $\mathrm{Mn}$ & & $16 \pm 6 \%$ & \\
\hline $\mathrm{Na}$ & & $42 \pm 12 \%$ & \\
\hline V & & $4.9 \pm 27 \%$ & \\
\hline As & & $2.0 \pm 34 \%$ & 2 \\
\hline $\mathrm{Cd}$ & & $0.1 \pm 34 \%$ & 0.5 \\
\hline $\mathrm{Cr}$ & & $3.2 \pm 26 \%$ & 6 \\
\hline $\mathrm{Cu}$ & & $5.7 \pm 16 \%$ & 3 \\
\hline $\mathrm{Ni}$ & & $3.6 \pm 19 \%$ & 4 \\
\hline $\mathrm{Pb}$ & & $6.0 \pm 24 \%$ & 32 \\
\hline Zn & & $20 \pm 17 \%$ & 23 \\
\hline Acenaphtene & & $0.74 \pm 40 \%$ & \\
\hline Acenaphtylene & & $0.02 \pm 40 \%$ & \\
\hline Anthracene & & $0.33 \pm 40 \%$ & \\
\hline Benzo(a)anthracene & & $0.28 \pm 40 \%$ & \\
\hline Benzo(a)pyrene & & $0.12 \pm 40 \%$ & 0.02 \\
\hline Benzo(b)fluranthene & & $0.21 \pm 40 \%$ & \\
\hline Benzo(ghi)perylene & & $0.05 \pm 40 \%$ & \\
\hline Benzo(k)fluoranthene & & $0.06 \pm 40 \%$ & \\
\hline Dibenzo(a,h)anthracene & & $<0.020$ & \\
\hline Phenanthrene & & $2.6 \pm 40 \%$ & \\
\hline Fluoranthene & & $0.28 \pm 40 \%$ & \\
\hline Fluorene & & $1.1 \pm 40 \%$ & \\
\hline Indeno(1,2,3-cd)pyrene & & $0.02 \pm 40 \%$ & \\
\hline Chrysene & & $0.95 \pm 40 \%$ & \\
\hline Naphtalene & & $1.3 \pm 40 \%$ & \\
\hline Pyrene & & $2.1 \pm 40 \%$ & \\
\hline
\end{tabular}

Table 2 continued

\begin{tabular}{|c|c|c|c|}
\hline Characteristic & Units & Value & Russian QC \\
\hline$\overline{\mathrm{PAH} 16}$ & & 10 & \\
\hline PCB & & n.d. & \\
\hline$C_{5}-C_{8}$ & & $<5.0$ & \\
\hline $\mathrm{C}_{8}-\mathrm{C}_{10}$ & & $130 \pm 30 \%$ & \\
\hline$C_{10}-C_{12}$ & & $890 \pm 30 \%$ & \\
\hline$C_{12}-C_{16}$ & & $77,00 \pm 30 \%$ & \\
\hline$C_{16}-C_{35}$ & & $13,000 \pm 30 \%$ & \\
\hline THC, total & & 22,000 & 1000 \\
\hline
\end{tabular}

Russian soil quality criteria (QC) for inorganic and organic priority substances are included

or other organic material, which excludes contamination from naturally occurring hydrocarbons, indicating that the high hydrocarbon content is related to oil pollution. The soil had elevated concentrations of PAH exemplified by benzo(a)pyrene which had a sixfold concentration compared to soil quality criteria. No PCB (7 congeners) was detected and the concentrations of heavy metals are low and may be naturally occurring rather than due to anthropogenic sources. The targeted pollutants in this study were hydrocarbons and PAH components. The PAH component, dibenzo(a,h)anthracene, and the THC fraction $\mathrm{C}_{5}-\mathrm{C}_{8}$, were not detected and are not included in further analysis of the experiments.

Ratios of selected PAH components have been widely used to identify specific sources and although results may be ambiguous, they provide indicative values (Countway et al. 2003; Feng et al. 2014; Pedersen et al. 2015a; Soclo et al. 2000; Yunker et al. 2002). In cases of PAH pollution from several sources, the ratios may be used for evaluating predominant sources. The ratio of anthracene/ (anthracene and phenanthrene) has previously been used for determining petrogenic $(<0.1)$ and pyrogenic $(>0.1)$ sources (Soclo et al. 2000). In this study the ratio was 0.1 and hence in the borderline of petrogenic and pyrogenic sources. The PAH ratios fluoranthene/(fluoranthene and pyrene) and indeno(123-cd)pyrene/(indeno(1,2,3-cd)pyrene and benzo(ghi)perylene) have been used to indicate whether pyrogenic sources originate from liquid fossil fuel combustion (0.4-0.5/0.2-0.5) or coal/biomass combustion $(>0.5 />0.5)$ (Feng et al. 2014). In this study these ratios were 0.1 and 0.3 , respectively, indicating that the source to be combustion of liquid fossil fuel. It is hence highly likely that the PAH pollution found at the site is related to the oil pollution at the site.

\section{Evaluation of EDR experiments}

During the EDR experiments, high voltages were registered, occasionally above $100 \mathrm{~V}$, in experiments no. 2 , 
4, 6 and 8, and employing a current density of $0.1 \mathrm{~mA} /$ $\mathrm{cm}^{2}$ was the limit of the equipment used. Low and steady voltages, generally below $2 \mathrm{~V}$, were observed in the centre point experiments (no. 9-12). The reason for the fluctuations and high levels of voltage in the experiments conducted at $0.1 \mathrm{~mA} / \mathrm{cm}^{2}$ may be due to the high concentration of oil products in the soil suspensions (Table 2) resulting in a low conductivity. During all experiments, thick dark brown/black oil was formed in the sediment compartment and this was hypothesized to be due to biodegradation of the original oil in the soil.

The $\mathrm{pH}$ in the experiments fluctuated between 2 and 4, with no clear indication of the influence of current. There was in addition no clear pattern in the increase and/or decrease in the $\mathrm{pH}$ during the experiments. Since concentrations of $\mathrm{Al}$, which can act as a buffer around $\mathrm{pH}$ 4 , was low, this may indicate that the high content of oil acted as buffer in the soil.

The concentration of some of the elements appeared to decrease during the experiments and in order to ascertain whether the observed differences were statistically significant, one factor variance analysis was undertaken. The final concentrations of $\mathrm{Al}, \mathrm{Ca}, \mathrm{Fe}, \mathrm{Mg}, \mathrm{Ni}$ and $\mathrm{Zn}$ were significantly lower after remediation experiments, while the $\mathrm{F}$ values of $\mathrm{Ba}, \mathrm{K}, \mathrm{Mn}, \mathrm{Na}, \mathrm{As}, \mathrm{Cd}, \mathrm{Cr}, \mathrm{Cu}$ and $\mathrm{Pb}$ were below the critical value (3.98). It was not possible to determine whether the metals removed stemmed from the oil or were naturally occurring in the soil matrix.

The removal efficiencies of total THC in the 12 experiments were $30-70 \%$ (Fig. 1). The highest removal efficiency was observed in experiment $8(432 \mathrm{~h} ; 0.01 \mathrm{~mA}$; $2 \mathrm{~mL} / \mathrm{g} ; 1300 \mathrm{rpm}$; light) and the lowest removal efficiency was detected in experiment 3 (432 h; no current; $4 \mathrm{~mL} / \mathrm{g} ; 100 \mathrm{rpm}$; light). Apart from experiment 11, the removal efficiencies appear to be higher in the experiments conducted at the centre point of the continuous variables. Microbial communities could be inhibited by high voltage gradients (Gill et al. 2014; Lohner et al. 2009; Wick 2009), observed in experiments 1, 3, 5, and 7 ; the higher removal efficiencies in the centre experiments with low voltage gradients, may be an indication of such an effect. The difference between the centre point experiments and the experiments in which no current was applied could be an effect of microbial degradation induced by the electric field, in line with previous findings (Dong et al. 2013; Kim et al. 2010).

Removal of the heavier THC fractions $\left(\mathrm{C}_{12}-\mathrm{C}_{16}\right.$ and $\mathrm{C}_{16}-\mathrm{C}_{35}$ ) and the total THC followed the same trend
(Fig. 1a) and is likely due to more than $95 \%$ total THC being found in these fractions. Even though large fluctuations were observed in the lighter fractions, this did not affect the total THC removal as the initial concentrations were low. In general, higher removal efficiencies of the lighter fractions $\left(\mathrm{C}_{8}-\mathrm{C}_{10}\right.$ and $\left.\mathrm{C}_{10}-\mathrm{C}_{12}\right)$ were observed, in line with results of an EK study of diesel polluted soil, in which the highest degradation of the $C_{10}-C_{16}$ fraction was reported (Kim et al. 2010). In the present study, degradation of the lighter fractions appears to be related to stirring rate; the highest removal efficiencies observed at medium-high stirring rates (experiments $1,4,5,8,9,11$ and 12). In experiments 6,7 and 10 removal efficiencies of the lighter fractions were lower compared to the total removal. In experiments 6 and 7 the low stirring rates and low $\mathrm{L} / \mathrm{S}$ ratios were applied indicating that not enough aeration was provided to remove the lighter fractions. The difference in removal efficiencies between experiment 10 and the other 3 experiments conducted in the centre point of the continuous variables may indicate an inhomogeneous distribution of the oil pollution in the soil.

Despite the variation in the removal efficiencies depending on the experimental settings, the distribution of the THC fractions were similar after the experiments; the exceptions being experiment 6, 7, 9 and 10 (Fig. 2b). In experiment 9 , the deviation is related to relatively larger removal of lighter fractions; albeit assessed to be within the experimental deviation. The distribution patterns of experiments 6,7 , and 10 are in line with observations of the removal efficiency trends of the different fractions revealing relatively less removal of the lighter fractions compared to the other experiments. Based on the observations of removal efficiencies and differences in trends and distribution of the THC fractions in the experiments, it was at this point not possible to deduce which parameters had the highest influence on the remediation (vide infra).

The removal efficiencies of total PAH16 were 10-65 \% (Fig. 3d) with the highest removal efficiencies ( $>40 \%$ ) observed in experiments 1,8 and the centre point experiments. Differences in the removal trends of the different PAH components were however observed and could be related to the number of aromatic rings of the PAH (Fig. $3 a-c)$. For the PAH containing 2-3 aromatic rings, the highest removal efficiencies were generally observed in experiments with medium-high stirring rates $(1,4$, $5,8-12)$. The removal efficiencies of these components were generally similar; fluoranthene, with the highest 


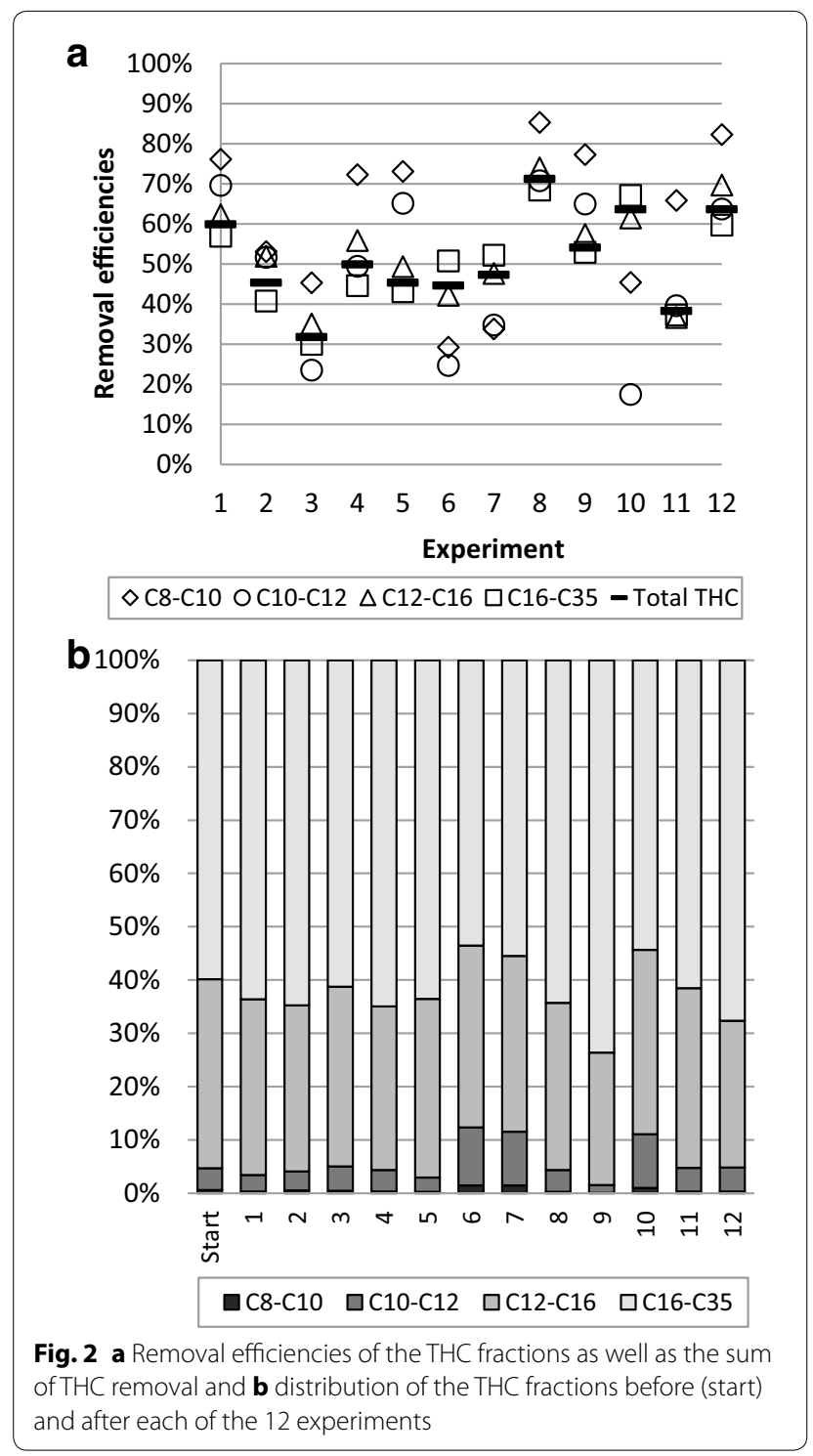

molecular weight in the group, consistently had the lowest removal efficiencies. Larger variations in the removal efficiencies were observed for PAH compounds containing 3-4 aromatic rings; although generally following the same trend between the experiments. Benzo(k)fluoranthene deviated the most from the general trend and was effectively removed. The deviations may be related to the low initial concentrations resulting in relatively larger errors in analyses. Apart from benzo(k)fluoranthene, the highest removal efficiencies of the PAH compounds with 3-4 aromatic rings were observed in experiments 1 and $8-12$. For the PAH compounds containing 5 aromatic rings there was no clear trend in removal efficiencies. The highest removal efficiencies of benzo(a)pyrene was observed in the experiments with medium-high stirring rates $(1,4,5,8-12)$. The generally higher variation in removal in the centre point experiments may indicate inhomogeneous distribution of PAH in the soil.

In order to assess the distribution of PAH components before and after the experiments, a PCA model was calculated. The model explained $96 \%$ (R2X) of the variation (Q2 $92 \%$ ). The scores plot revealed different distribution of the PAH components after the experiments and were to some degree clustered according to the experimental settings (Fig. 4). The centre point experiments, apart from experiment 10, which was previously shown to deviate, were clustered in the left side of the scores plot. The experiments run at high stirring rates (apart from experiment 4) were clustered in the centre part of the scores plot. Experiments 6 and 7 had the lowest removal efficiencies and were also located close to one another. The PCA plot hence indicates that stirring rate may influence the remediation; multivariate investigations are however necessary to confirm these observations.

\section{Variable importance}

In order to determine variable importance in the remediation, two PLS models of the final concentrations in the experiments were calculated:

Model 1: PAH components were inserted as responses.

Model 2: The fractions of hydrocarbons were inserted as responses.

Model 1 had a correlation factor, R2Y, of 0.89 and a predictive power, Q2, of 0.69 and was hence assessed as a good and stable model suitable for evaluation of variable importance in the experiments. Model 2 had a R2Y value of 0.62 and Q2 value of 0.26 and was hence a more instable model, but was none the less assessed as having an indicative value of variable importance.

For both the degradation of PAH components and hydrocarbon fractions, as indicated by the preliminary assessments, the stirring rate was with VIP values above 1 by far the most important parameter (Fig. 5). Light appears to have a relatively higher influence on the degradation of $\mathrm{PAH}$ components than the hydrocarbon 


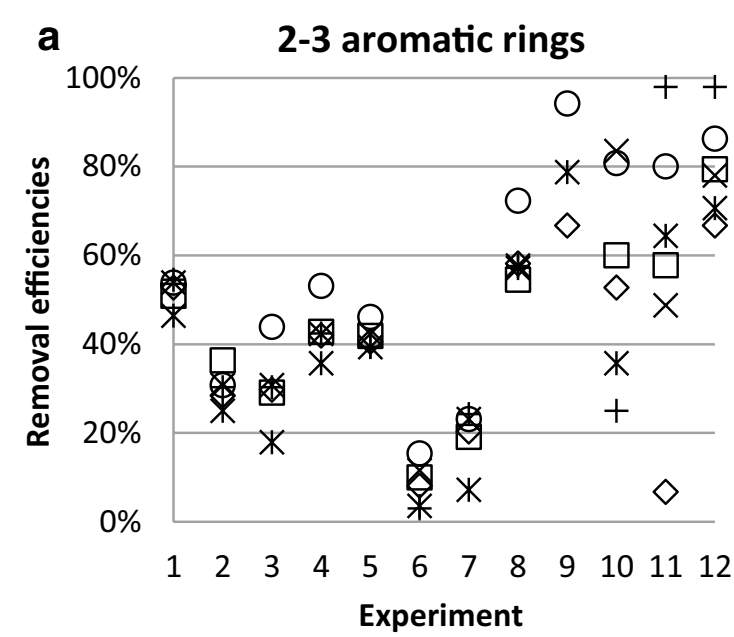

\begin{tabular}{|lll|}
\hline Acenaphtene & + Antracene & XFluoranthene \\
$\square$ Fluorene & ONaphtalene & XPhenanthrene
\end{tabular}

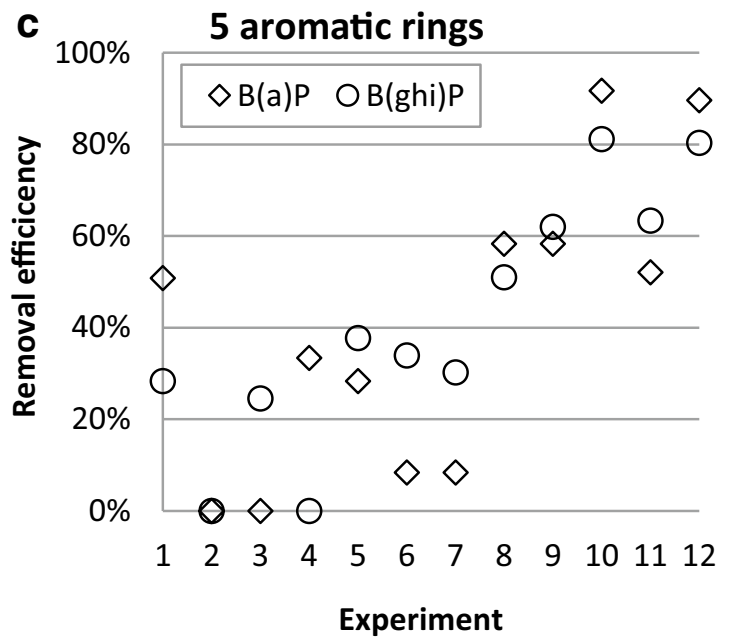

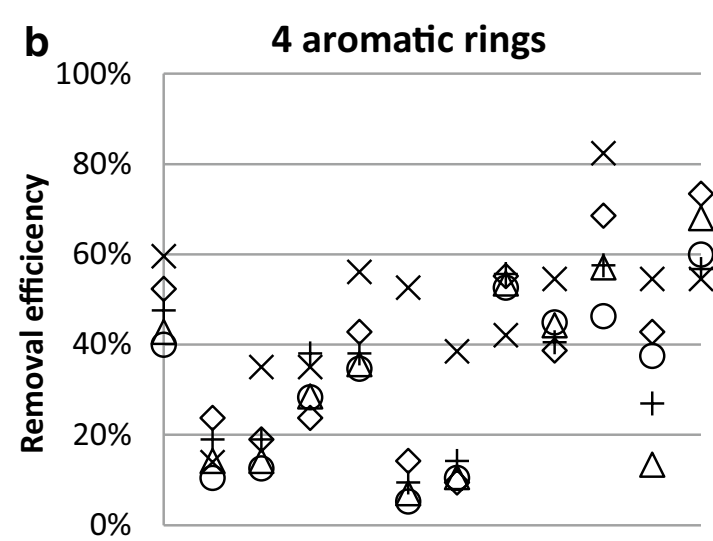

$\begin{array}{llllllllllll}1 & 2 & 3 & 4 & 5 & 6 & 7 & 8 & 9 & 10 & 11 & 12\end{array}$

Experiment

\begin{tabular}{|lll|}
$\triangle \mathrm{B}(\mathrm{a}) \mathrm{A}$ & $\diamond \mathrm{B}(\mathrm{b}) \mathrm{F}$ & $\times \mathrm{B}(\mathrm{k}) \mathrm{F}$ \\
OChrysene & + Pyrene & \\
\hline
\end{tabular}

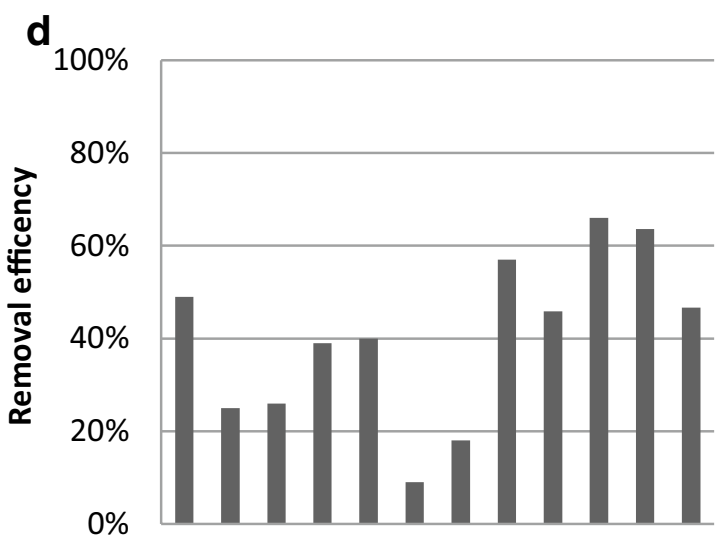

$\begin{array}{llllllllllll}1 & 2 & 3 & 4 & 5 & 6 & 7 & 8 & 9 & 10 & 11 & 12\end{array}$

Experiment

Fig. 3 Removal efficiencies of PAH components; a containing 2-3 aromatic rings, $\mathbf{b}$ containing 4 aromatic rings, $\mathbf{c}$ containing 5 aromatic rings and d Sum of PAH16. $B(a) A$ benzo(a)anthracene, $B(b) F$ benzo(b)fluoranthene, $B(k) F$ benzo(k)fluoranthene, $B(a) P$ benzo(a)pyrene; and $B(g h i) P$ benzo(ghi) perylene

chains; the effect (VIP value $\sim 0.6$ ) however not as significant as the stirring rate. The $\mathrm{L} / \mathrm{S}$ ratio had a relatively higher influence (VIP value $\sim 0.6$ ) on the degradation of hydrocarbons; coefficient plots of the four hydrocarbon fractions revealed that a low $\mathrm{L} / \mathrm{S}$ ratio increased removal efficiencies. This may be an indication of a limiting amount of suspension liquid for increasing bioavailability of the hydrocarbons.

For both PAH components and the THC fractions, current density and time had low influences on the final concentrations (VIP values below 0.5), indicating that the EDR process itself did not significantly affect the degradation of organic contaminants within the experimental domain studied. Previous studies found that applying current to soil may stimulate microbial activity and enhance cell respiration, mainly attributed to production of oxygen at the anode (Kim et al. 2010); however this effect was not detectable in this study, which could be due to the anion exchange membrane preventing introduction of oxygen produced at the anode, or that aeration of the soil suspension by stirring rate introduced more oxygen than was produced at the anode. In an 


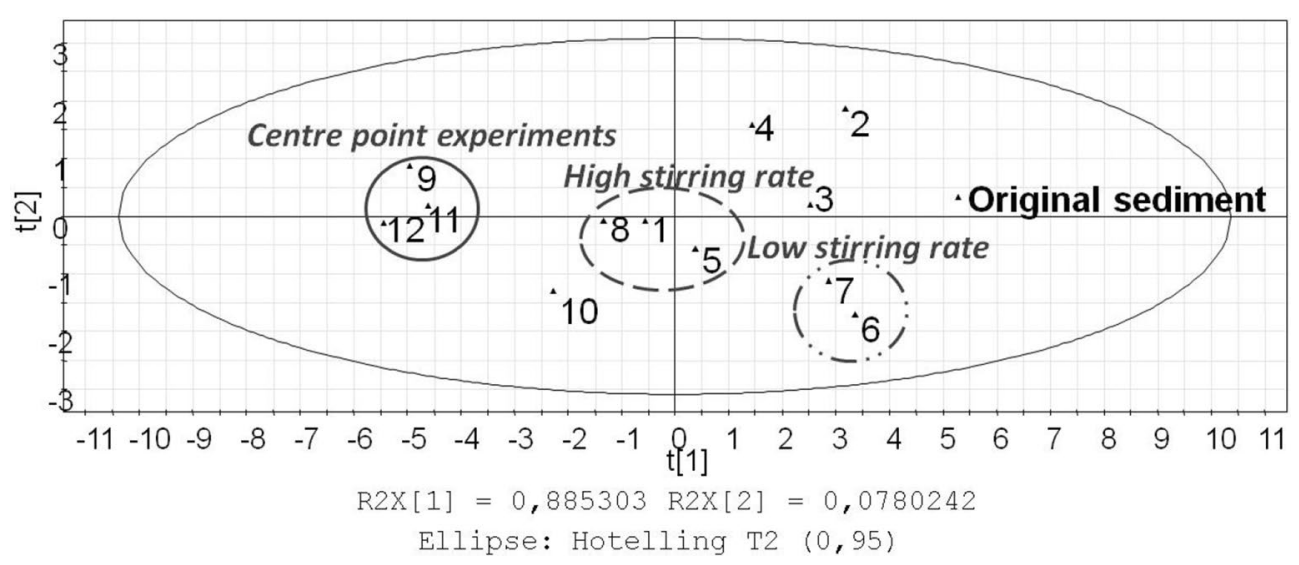

Fig. 4 PCA scores plot of PAH component concentrations before (original sediment) and after experiments 1-12

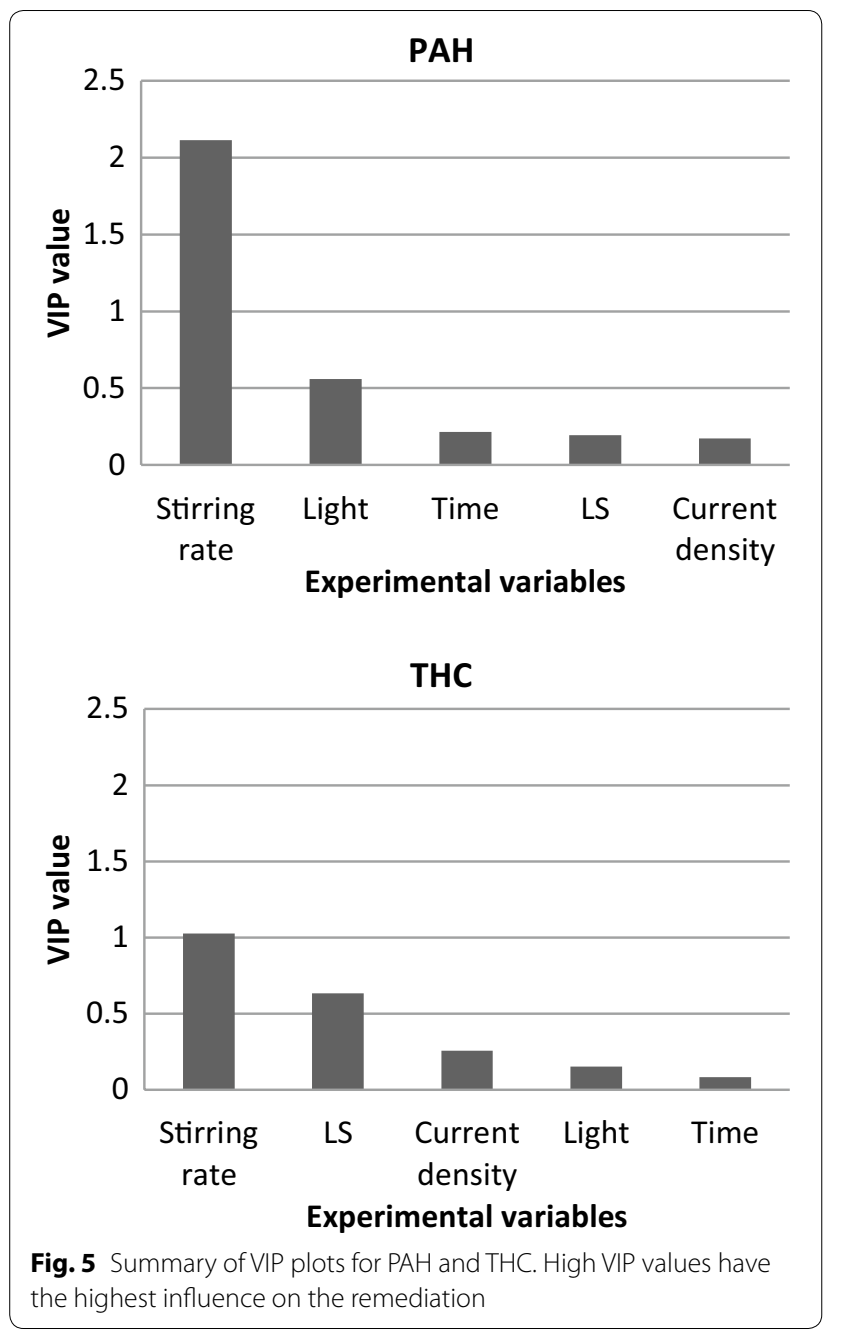

EKR coupled with bioremediation study, the initial fast degradation rate of $\mathrm{PAH}$, was followed by a slower degradation rate ( $\mathrm{Li}$ et al. 2012). In this study, the fast degradation may have occurred within the first $48 \mathrm{~h}$, after which the influence of time on the removal efficiencies is negligible. In addition, the electrodialytic process may have depleted the soil suspension of nutrients. The $\mathrm{pH}$ in the soil suspensions did not decrease during EDR; microbial communities adapted to the initially high concentrations of oil were hence not inhibited by an increasing acidification during treatment and may be a reason for the high removal efficiencies achieved. From this study it is however not possible to assess the relative relation between bioremediation, volatilisation of oil compounds and transfer of pollutants to the water phase. Nonetheless, since the stirring rate has a significantly higher influence than light, this indicates that bioremediation and/or volatilisation was more significant than degradation by photolysis.

\section{Conclusions}

The study indicated that simultaneous removal of organic pollutants during electrodialytic removal of heavy metals is possible. Depending on the remediation objective; e.g. if the organic pollutant concentrations should meet soil quality criteria, remediation strategies may include further optimisation steps to obtain these. For future design of simultaneous electrodialytic removal of heavy metals and organic pollutants it appears imperative to apply stirred set-ups and further optimisation could be achieved by stimulating further bioremediation, e.g. by adding nutrients and/or microorganisms. 


\section{Authors' contributions}

KBP carried out all of the experimental work, including calculations, and drafted the manuscript. TL participated in calculations and finalization of the manuscript. PEJ participated in the electrochemistry experiments and drafting the paper. LMO participated in the experiments concerning electrochemistry and in drafting the paper. All authors read and approved the final manuscript.

\section{Author details}

${ }^{1}$ Department of Chemistry, University of Troms $\varnothing$, The Arctic University of Norway, Postbox 6050, 9037 Langnes, Troms $\varnothing$, Norway. ${ }^{2}$ Department of Civil Engineering, Arctic Technology Centre, Technical University of Denmark, Brovej Building 118, 2800 Lyngby, Denmark.

\section{Acknowledgements}

The Northern Environmental Waste Management (EWMA) project, which is funded by the Research Council of Norway through NORDSATSNING (Grant number 195160) and Eni Norge AS, is acknowledged for funding. Naida Murtazalieva is acknowledged for assistance in sampling and transport of the samples from Arkhangelsk.

\section{Competing interests}

The authors declare that they have no competing interests.

Received: 24 September 2015 Accepted: 16 February 2016 Published online: 24 February 2016

\section{References}

Abdi H (2010) Partial least squares regression and projection on latent structure regression (PLS regression). Wiley Interdiscip Rev Comput Stat 2:97-106

Acar YB, Alshawabkeh AN (1993) Principles of electrokinetic remediation. Environ Sci Technol 27:2638

Acar YB, Alshawabkeh AN, Gale RJ (1993) Fundamentals of extracting species from soils by electrokinetics. Waste Manag 13:141-151

Carlson R, Carlson JE (2005) Design and optimisation in organic synthesis. Elsevier, Amsterdam

Colacicco A, De Gioannis G, Muntoni A, Pettinao E, Polettini A, Pomi R (2010) Enhanced electrokinetic treatment of marine sediments contaminated by heavy metals and PAHs. Chemosphere 81:46-56

Countway RE, Dickhut RM, Canuel EA (2003) Polycyclic aromatic hydrocarbon (PAH) distributions and associations with organic matter in surface waters of the York River, VA Estuary. Org Geochem 34:209-224

Dong Z-Y, Huang W-H, Xing D-F, Zhang H-F (2013) Remediation of soil cocontaminated with petroleum and heavy metals by the integration of electrokinetics and biostimulation. J Hazard Mater 260:399-408

Feng J, Li X, Guo W, Liu S, Ren X, Sun J (2014) 'Potential source apportionment of polycyclic aromatic hydrocarbons in surface sediments from the middle and lower reaches of the Yellow River, China. Environ Sci Pollut R 21:11447-11456

Gill RT, Harbottle MJ, Smith JWN, Thornton SF (2014) Electrokinetic-enhanced bioremediation of organic contaminants: a review of processes and environmental applications. Chemosphere 107:31-42

Kim SH, Han HY, Lee YJ, Kim CW, Yang JW (2010) Effect of electrokinetic remediation on indigenous microbial activity and community within diesel contaminated soil. Sci Total Environ 408:3162-3168

Li F, Guo S, Hartog N (2012) Electrokinetics-enhanced biodegradation of heavy polycyclic aromatic hydrocarbons in soil around iron and steel industries. Electrochim Acta 85:228-234

Lima AT, Ottosen LM, Heister K, Loch JPG (2012) Assessing PAH removal from clayey soil by means of electro-osmosis and electrodialysis. Sci Total Environ 435-436:1-6

Lohner ST, Tiehm A, Jackman SA, Carter P (2009) Coupled electrokinetic-bioremediation: applied aspects, electrochemical remediation technologies for polluted soils, sediments and groundwater. Wiley, New York, pp 389-416

Mena E, Villaseñor J, Cañizares P, Rodrigo MA (2014) Effect of a direct electric current on the activity of a hydrocarbon-degrading microorganism culture used as the flushing liquid in soil remediation processes. Sep Purif Technol 124:217-223

Niqui-Arroyo J-L, Bueno-Montes M, Posada-Baquero R, Ortega-Calvo J-J (2006) Electrokinetic enhancement of phenanthrene biodegradation in creosote-polluted clay soil. Environ Pollut 142:326-332

Ottosen LM, Hansen HK, Laursen S, Villumsen A (1997) Electrodialytic remediation of soil polluted with copper from wood preservation industry. Environ Sci Technol 31:1711-1715

Ottosen LM, Hansen HK, Hansen CB (2000) Water splitting at ion-exchange membranes and potential differences in soil during electrodialytic soil remediation. J Appl Electrochem 30:1199-1207

Ottosen LM, Jensen PE, Kirkelund GM, Ferreira CD, Hansen HK (2012) Electrodialytic remediation of heavy metal polluted soil —-treatment of water saturated or suspended soil. Chem Eng Trans 28:103-108

Pedersen K, Lejon T, Jensen P, Ottosen L (2015a) Chemometric analysis for pollution source assessment of harbour sediments in arctic locations. Water Air Soil Pollut 226:1-15

Pedersen KB, Kirkelund GM, Ottosen LM, Jensen PE, Lejon T (2015b) Multivariate methods for evaluating the efficiency of electrodialytic removal of heavy metals from polluted harbour sediments. J Hazard Mater 283:712-720

Pedersen KB, Lejon T, Ottosen LM, Jensen PE (2015c) Screening of variable importance for optimizing electrodialytic remediation of heavy metals from polluted harbour sediments. Environ Technol 36:2364-2373

Pedersen KB, Ottosen LM, Jensen PE, Lejon T (2015d) Comparison of 2-compartment, 3-compartment and stack designs for electrodialytic removal of heavy metals from harbour sediments. Electrochim Acta 181:48-57

Schmidt CAB, Barbosa MC, de Almeida MdSS (2007) A laboratory feasibility study on electrokinetic injection of nutrients on an organic, tropical, clayey soil. J Hazard Mater 143:655-661

Shi L, Müller S, Harms H, Wick L (2008a) Effect of electrokinetic transport on the vulnerability of PAH-degrading bacteria in a model aquifer. Environ Geochem Health 30:177-182

Shi L, Müller S, Loffhagen N, Harms H, Wick LY (2008b) Activity and viability of polycyclic aromatic hydrocarbon-degrading Sphingomonas sp. LB126 in a DC-electrical field typical for electrobioremediation measures. Microb Biotechnol 1:53-61

Soclo HH, Garrigues P, Ewald M (2000) Origin of polycyclic aromatic hydrocarbons (PAHs) in coastal marine sediments: case studies in Cotonou (Benin) and Aquitaine (France) areas. Mar Pollut Bull 40:387-396

Trygg J, Wold S (2002) Orthogonal projections to latent structures (O-PLS). J Chemom 16:119-128

Wang J, Li F, Li X, Wang X, Li X, Su Z, Zhang H, Guo S (2013) Effects of electrokinetic operation mode on removal of polycyclic aromatic hydrocarbons (PAHs), and the indigenous fungal community in PAH-contaminated soil. J Environ Sci Health A 48:1677-1684

Wick LY (2009) Coupling electrokinetics to the bioremediation of organic contaminants: principles and fundamental interactions', electrochemical remediation technologies for polluted soils, sediments and groundwater. Wiley, New York, pp 367-387

Wick LY, Mattle PA, Wattiau P, Harms H (2004) Electrokinetic transport of PAH-degrading bacteria in model aquifers and soil. Environ Sci Technol 38:4596-4602

Wold S, Sjöström M, Eriksson L (2001) PLS-regression: a basic tool of chemometrics. Chemometr Intell Lab Syst 58:109-130

Yunker MB, Macdonald RW, Vingarzan R, Mitchell RH, Goyette D, Sylvestre S (2002) PAHs in the Fraser River basin: a critical appraisal of PAH ratios as indicators of PAH source and composition. Org Geochem 33:489-515 